\title{
Group B streptococcal colonization in elderly women
}

\author{
Rossella Baldan', Sara Droz ${ }^{1}$, Carlo Casanova', Laura Knabben², Dorothy J. Huang ${ }^{3}$, Christine Brülisauer', \\ André B. Kind ${ }^{3}$, Elke Krause ${ }^{2}$, Stefanie Mauerer ${ }^{4}$, Barbara Spellerberg ${ }^{4}$ and Parham Sendi ${ }^{1,5^{*}}$ (D)
}

\begin{abstract}
Background: In non-pregnant adults, the incidence of invasive Group B Streptococcus (GBS) disease is continuously increasing. Elderly and immunocompromised persons are at increased risk of infection. GBS commonly colonizes the vaginal tract, though data on colonization in the elderly are scarce. It is unknown whether the prevalence of GBS colonization is increasing in parallel to the observed rise of invasive infection. We conducted a three-year (2017-2019) prospective observational cross-sectional study in two teaching hospitals in Switzerland to determine the rate of GBS vaginal colonization in women over 60 years and i) to compare the proportions of known risk factors associated with invasive GBS diseases in colonized versus non-colonized women and ii) to evaluate the presence of GBS clusters with specific phenotypic and genotypic patterns in this population.

Methods: GBS screening was performed by using vaginal swabs collected during routine examination from women willing to participate in the study and to complete a questionnaire for risk factors. Isolates were characterized for antibiotic resistance profile, serotype and sequence type (ST).

Results: The GBS positivity rate in the elderly was 17\% (44/255 positive samples), and similar to the one previously reported in pregnant women (around 20\%). We could not find any association between participants' characteristics, previously published risk factors and GBS colonization. All strains were susceptible to penicillin, 22\% (8/36) were not susceptible to erythromycin, 14\% (5/36) were not susceptible to clindamycin and 8\% (3/36) showed inducible clindamycin resistance. Both $\mathrm{M}$ and $\mathrm{L}$ phenotypes were each detected in one isolate. The most prevalent serotypes were III $(33 \%, 12 / 36)$ and V $(31 \%, 11 / 36)$. ST1 and ST19 accounted for $11 \%$ of isolates each $(4 / 36)$; ST175 for $8 \%$ (3/ 36); and ST23, ST249 and ST297 for 6\% each (2/36). Significantly higher rates of resistance to macrolides and clindamycin were associated with the ST1 genetic background of ST1.
\end{abstract}

Conclusions: Our findings indicate a similar colonization rate for pregnant and elderly women.

Trial registration: Current Controlled Trial ISRCTN15468519; 06/01/2017

Keywords: Group B Streptococcus, Streptococcus agalactiae, Colonization, Elderly women, Postmenopausal women

\footnotetext{
* Correspondence: parham.sendi@ifik.unibe.ch

'Institute for Infectious Diseases, University of Bern, Friedbühlstrasse 51, 3010 Bern, Switzerland

${ }^{5}$ Division of Infectious Diseases \& Hospital Hygiene, University Hospital Basel and University of Basel, Basel, Switzerland

Full list of author information is available at the end of the article
}

(C) The Author(s). 2021 Open Access This article is licensed under a Creative Commons Attribution 4.0 International License, which permits use, sharing, adaptation, distribution and reproduction in any medium or format, as long as you give appropriate credit to the original author(s) and the source, provide a link to the Creative Commons licence, and indicate if changes were made. The images or other third party material in this article are included in the article's Creative Commons licence, unless indicated otherwise in a credit line to the material. If material is not included in the article's Creative Commons licence and your intended use is not permitted by statutory regulation or exceeds the permitted use, you will need to obtain permission directly from the copyright holder. To view a copy of this licence, visit http://creativecommons.org/licenses/by/4.0/ The Creative Commons Public Domain Dedication waiver (http://creativecommons.org/publicdomain/zero/1.0/) applies to the data made available in this article, unless otherwise stated in a credit line to the data. 


\section{Background}

Group B Streptococcus (GBS, Streptococcus agalactiae) is a pathobiont frequently found in the normal microbiota of the gastrointestinal and vaginal tracts of women $[1,2]$. GBS can cause life-threatening infections in neonates, with maternal colonization being the principal route of transmission. In non-pregnant adults, the incidence of infection is continuously increasing [3, 4]. Elderly and immunocompromised persons with underlying conditions, such as diabetes mellitus and cancer, are at increased risk of invasive GBS disease [4-6]. A Danish study showed that from 2005 to 2018, the incidence of invasive GBS in adults aged 65-74 years increased from 3.23 to 8.34 per 100,000 , and in adults over 75 years from 6.85 to 16.01 per 100,000 [7]. Their finding aligns with data from Iceland, Finland, Norway, England and Wales, Canada, and other countries [8-12]. Skin and soft-tissue infection, primary bacteraemia and urinary tract infection are the most frequent clinical manifestations of invasive GBS disease in the elderly [13, 14]. Most studies have investigated the prevalence of GBS colonization in pregnant women, only a few focusing on non-pregnant adults [13, 15]. Vaginal colonization in pregnant women worldwide ranges between 5 and 30\%$35 \%$, with an average estimate of approximately $20 \%$ [14, 16]. In contrast, little is known about the GBS colonization rate in women older than 60 years of age. It is unknown whether the prevalence of GBS colonization is increasing in parallel to the observed rise of invasive infection. The site of GBS colonization could potentially be the source of invasive infection, underscoring the importance to investigating the colonization rate in this patient population.

We present here the results of a prospective observational cross-sectional study in which we aimed to determine the vaginal colonization rate in women over the age of 60 in two teaching hospitals in Switzerland. Secondary objectives of the study were to compare the proportions of known risk factors associated with invasive GBS diseases in colonized versus non-colonized women and to evaluate the presence of clusters with specific phenotypic and genotypic patterns in GBS strains isolated in our population.

\section{Methods}

\section{Study design and participants' data}

Women presenting at the outpatient clinic of two centres (Bern and Basel University hospitals) for a routine vaginal examination between January 2017 and December 2019 were screened for eligibility. Participants to be included in the study had to be $\geq 60$ years old and capable of reading and understanding the patient information sheet and giving voluntary written consent to participate in the study, in which a vaginal swab would be collected during their routine gynaecological examination and cultured for the presence of GBS. In addition, participants were asked to complete a short questionnaire to obtain data regarding ethnicity, current or prior medical conditions, menstrual history and sexual history (Supplementary Material). Patient consent, study information and questionnaires were available in four languages (German, French, Italian and English). The swab and the questionnaire were coded to protect participants' identifiable data and privacy, according to the approved study protocol (trial registration no. ISRC TN15468519). The study was approved by the local ethical committee (Kantonale Ethikkommission-Bern: 2016-01669).

\section{GBS culture and characterization}

GBS screening was carried out with the same methodology throughout the whole study period. Isolation of the strain from vaginal samples was performed by growth in an enrichment medium (Todd-Hewitt broth) followed by subculture on a selective GBS chromagar plate (StrepB, CHROMagarTM, Paris, France). Identified colonies were subjected to MALDI-TOF mass spectrometry.

GBS isolates were further characterized at the phenotypic and genotypic level to determine the antibiotic resistance profile, the capsular serotype and the clone sequence type (ST). The minimal inhibitory concentrations (MICs) for penicillin, clindamycin and erythromycin were determined by E-test (bioMérieux, Marcy l'Etoile, France) and interpreted according to CLSI guidelines [17]. Detection of the macrolide-lincosamidestreptogramin $\mathrm{B}\left(\mathrm{MLS}_{\mathrm{B}}\right)$ resistance phenotype was assessed by double disk diffusion test $[18,19]$. Capsular serotyping was performed by use of a rapid latex agglutination test and polymerase chain reaction analysis, as previously described [20, 21] Sequence type was determined by multilocus sequence typing as described elsewhere (https://pubmlst.org/sagalactiae/). One sample per patient was included in the analysis. In the case of multiple sampling from the same participant, only the swab obtained at the first visit was analysed.

\section{Data analysis}

Questionnaire and microbiology data were recorded in an electronic database designed with REDCap software (Research Electronic Data CAPture). Significant associations between participants' characteristics/risk factors, GBS carrier status, GBS antibiotic resistance profiles, serotypes and sequence types were investigated. In the case of missing answers per single question, the denominator for each analysis was adapted accordingly. GraphPad Prism 8.0 was used for statistical analysis. The association between age variables and a positive GBS 
result was investigated by using the Mann-Whitney test. Differences in the prevalence of risk factors between GBS-positive and GBS-negative groups were assessed by contingency tables and the chi-square test, or by Fisher's exact probability test if the frequency was less than 5 . For direct comparisons, distribution analyses were also performed by using the chi-square test, Fisher's exact test or Cochran-Armitage trend analysis. A two-tailed $p$ value of $\leq 0.05$ was considered significant.

\section{Results}

During the study period, 263 samples were collected from a total of 259 patients from the two centres, as shown in Fig. 1. Four samples were excluded from analysis, as they were obtained from the same patients during a second clinic visit. Another four were excluded because the samples could not be cultured. Thus, a total of 255 unique samples were included in the study.

Overall, the GBS positivity rate was $17 \%$ (44/255 positive samples), which was similar in both study sites (Bern centre: 18\%, 35/199; Basel centre: 16\%, 9/56). The results of the questionnaire data, including participants' demographic characteristics and risk factors for GBS colonization, were analysed overall and divided by GBS carrier status, a summary of which is shown in Table 1 . No significant associations were found between the participants' demographic characteristics, medical history, menstrual history, sexual activity and GBS status.
Of the 44 swabs that tested positive, 36 GBS isolates were available for phenotypic and genotypic characterization (Fig. 1). The results are presented in Table 2. All 36 GBS isolates were susceptible to penicillin, with an MIC ranging between 0.032 and $0.094 \mathrm{mg} / \mathrm{L}$. Eight GBS isolates (22\%) were not susceptible to erythromycin, and three of them $(3 / 8,37.5 \%)$ had a MIC of $\geq 256 \mathrm{mg} / \mathrm{L}$. Five isolates (14\%) were not susceptible to clindamycin, four of them $(4 / 5,80 \%)$ with a MIC of $\geq 256 \mathrm{mg} / \mathrm{L}$ and one with a MIC of $1.5 \mathrm{mg} / \mathrm{L}$. In addition, three GBS isolates $(8 \%)$ that were considered clindamycin susceptible by E-test (MIC $0.19 \mathrm{mg} / \mathrm{L}$ ) showed the $\mathrm{MLS}_{\mathrm{B}}$ phenotype when tested by the double disk diffusion test, indicating inducible clindamycin resistance. Hence, eight (22\%) GBS isolates were considered nonsusceptible to clindamycin. Twenty-seven GBS isolates (75\%) were susceptible to both clindamycin and erythromycin.

One GBS isolate belonging to capsular serotype Ia and ST624 (3\%) showed an M phenotype, with erythromycin resistance only (MIC $4 \mathrm{mg} / \mathrm{L}$ ). One GBS isolate assigned to capsular serotype III and ST19 (3\%) displayed the L phenotype, being resistant to clindamycin only (MIC 1.5 $\mathrm{mg} / \mathrm{L})$.

Capsular serotyping showed that the most prevalent serotypes were III $(33 \%, 12 / 36), \mathrm{V}(31 \%, 11 / 36)$ and Ia $(17 \%, 6 / 36)$. Multilocus sequence typing analysis showed that the most common sequence types were ST1 and

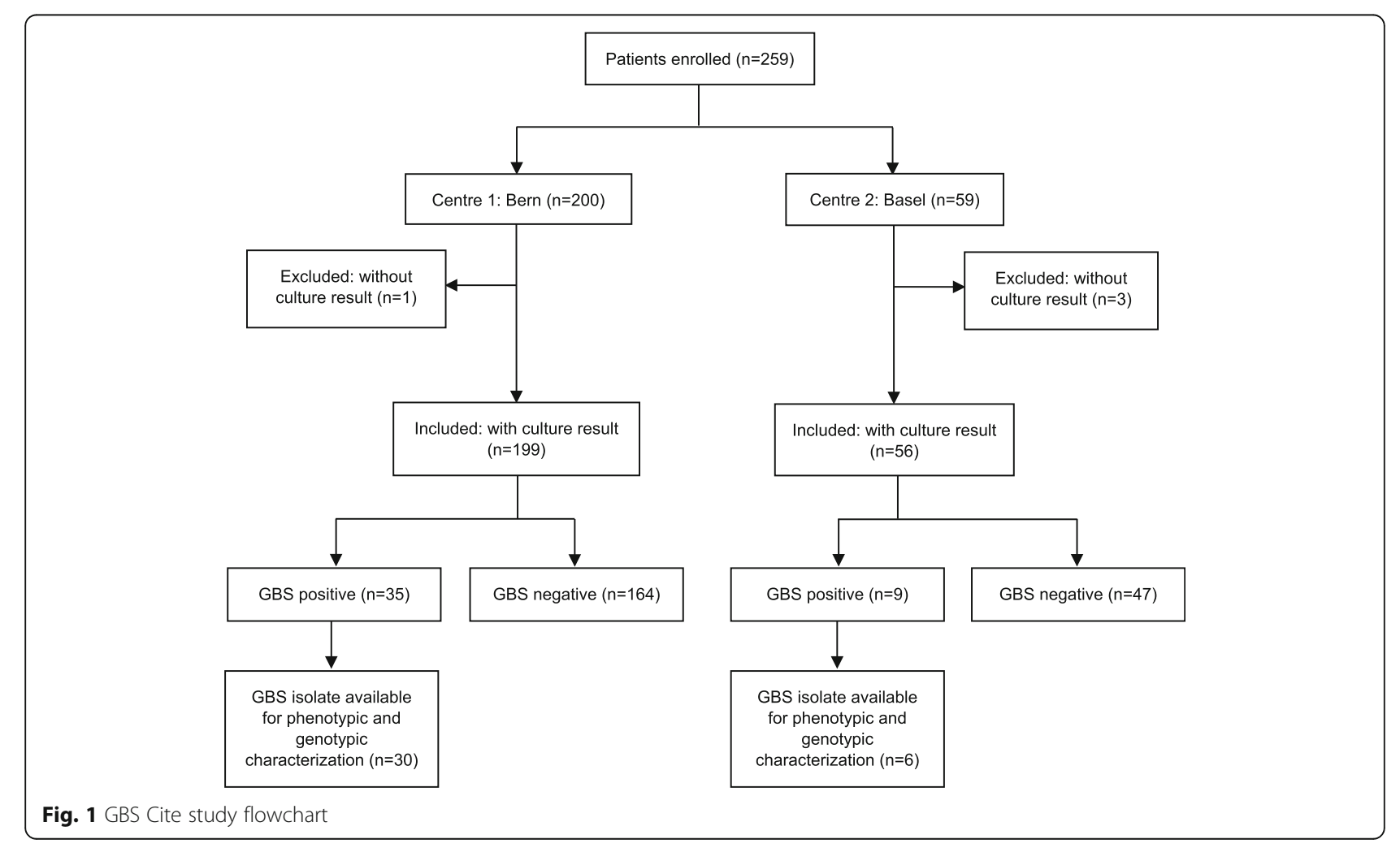


Table 1 Participants' demographic characteristics and risk factors for GBS acquisition overall and by GBS carrier status

\begin{tabular}{|c|c|c|c|c|}
\hline Participants' characteristics/risk factors & $\begin{array}{l}\text { Overall }(n= \\
255)\end{array}$ & $\begin{array}{l}\text { GBS positive }(n= \\
\text { 44) }\end{array}$ & $\begin{array}{l}\text { GBS negative }(n= \\
\text { 211) }\end{array}$ & $P$-Value \\
\hline \multicolumn{5}{|l|}{ Demographic characteristics } \\
\hline Mean age at enrolment (years, SD) & $68(6)$ & $68(5)$ & $69(6)$ & 0.59 \\
\hline Minimum-maximum age (years) & $69-98$ & $60-84$ & $60-98$ & $\mathrm{Na}$ \\
\hline Participants' origin & & & & $0.46^{*}$ \\
\hline Swiss (\%) & 205/239 (86\%) & 38/42 (90\%) & $167 / 197(85 \%)$ & \\
\hline Other (\%) & $34 / 239(14 \%)$ & $4 / 42(10 \%)$ & $30 / 197(15 \%)$ & \\
\hline Not answered (\%) & $16 / 255(6 \%)$ & $2 / 44(5 \%)$ & $14 / 255(7 \%)$ & $\mathrm{Na}$ \\
\hline \multicolumn{5}{|l|}{ Medical history } \\
\hline No. of participants with diabetes (\%) & $20 / 254(8 \%)$ & $3 / 44(7 \%)$ & $17 / 210(8 \%)$ & $>0.99^{*}$ \\
\hline No. of participants with liver disease (\%) & $7 / 253(3 \%)$ & 0/44 (0\%) & $7 / 209(3 \%)$ & $0.60^{*}$ \\
\hline No. of participants with history of stroke (\%) & $6 / 253(2 \%)$ & $1 / 44(2 \%)$ & $5 / 209(2 \%)$ & $>0.99^{*}$ \\
\hline No. of participants with bladder weakness (\%) & $84 / 246(34 \%)$ & 10/43 (23\%) & 74/203 (36\%) & 0.09 \\
\hline No. of participants with history of cancer (\%) & $43 / 251(17 \%)$ & 9/44 (20\%) & $34 / 207(16 \%)$ & 0.51 \\
\hline No. of participants still receiving cancer treatment (\%) & $17 / 39(44 \%)$ & $4 / 9(44 \%)$ & $13 / 30(43 \%)$ & $>0.99^{*}$ \\
\hline \multicolumn{5}{|l|}{ Menstruation } \\
\hline Mean age of first menstruation (years, SD) & $14(2)$ & $14(2)$ & $14(2)$ & 0.97 \\
\hline Not answered & $14 / 255$ & $1 / 44$ & $13 / 211$ & $\mathrm{Na}$ \\
\hline Mean age of menopause (years, SD) & $49(7)$ & $48(8)$ & $49(7)$ & 0.69 \\
\hline Not answered & $25 / 255$ & $2 / 44$ & $23 / 211$ & $\mathrm{Na}$ \\
\hline \multicolumn{5}{|l|}{ Sexual activity } \\
\hline No. of sexual partners during life & & & & $\begin{array}{l}0.73^{\S} / \\
0.80^{\circ}\end{array}$ \\
\hline 1 or less (\%) & $77 / 247(31 \%)$ & $13 / 42(31 \%)$ & $64 / 205$ (31\%) & 0.97 \\
\hline 2 or $3(\%)$ & $80 / 247(32 \%)$ & $14 / 42(33 \%)$ & $66 / 205$ (32\%) & 0.88 \\
\hline 3 or $4(\%)$ & $42 / 247(17 \%)$ & $5 / 42(12 \%)$ & $37 / 205(18 \%)$ & 0.33 \\
\hline 5 or more $(\%)$ & $48 / 247(20 \%)$ & $10 / 42(24 \%)$ & $38 / 205(19 \%)$ & 0.43 \\
\hline Not answered (\%) & $8 / 255(3 \%)$ & 2/44 (4\%) & $6 / 211(3 \%)$ & $\mathrm{Na}$ \\
\hline $\begin{array}{l}\text { No. of participants with a new sexual partner in the last few months } \\
\text { before enrolment }\end{array}$ & $11 / 255(4 \%)$ & $1 / 44(2 \%)$ & $10 / 211(5 \%)$ & $0.69^{*}$ \\
\hline No. of participants' sexual encounters in the 6 months before enrolment & & & & $\begin{array}{l}0.98^{\S * /} \\
0.65^{\circ}\end{array}$ \\
\hline 1 or less (\%) & $141 / 235(60 \%)$ & 24/41 (59\%) & $117 / 194(60 \%)$ & 0.83 \\
\hline 2 or $3(\%)$ & $15 / 235(6 \%)$ & 2/41 (4\%) & 13/194 (7\%) & $>0.99^{*}$ \\
\hline 3 or $4(\%)$ & $18 / 235(8 \%)$ & $3 / 41(7 \%)$ & 15/194 (8\%) & $>0.99^{*}$ \\
\hline At least once per month (\%) & $31 / 235(13 \%)$ & $6 / 41(15 \%)$ & 25/194 (13\%) & 0.76 \\
\hline At least once per week (\%) & $30 / 235(13 \%)$ & 6/41 (15\%) & 24/194 (12\%) & 0.69 \\
\hline Not answered (\%) & 20/255 (8\%) & $3 / 44(7 \%)$ & $17 / 211(8 \%)$ & $\mathrm{Na}$ \\
\hline
\end{tabular}

Association between age variables and GBS status was investigated by using the Mann-Whitney test; association between other risk factors and GBS status was assessed by using the chi-square test or Fisher's exact test (indicated by *); distribution analysis was also performed by using the chi-square test (indicated by $\S$ ), Fisher's exact test $\left(^{*}\right)$ or Cochran-Armitage trend analysis $\left({ }^{\circ}\right)$. In each analysis, the denominator includes only participants who provided the information; participants who did not answer the question were excluded. SD Standard deviation, Na Not applicable

ST19, accounting for four isolates each (11\%); ST175 with three isolates (8\%); and ST23, ST249 and ST297 with two isolates each (6\%). Five strains could not be assigned to a sequence type (no exact match, 14\%), while the remaining 14 isolates belonged to unique sequence types, including one to ST17 and capsular serotype III.

Compared with non-ST1 isolates, ST1 (serotype V) isolates were significantly associated with resistance to 
Table 2 Phenotypic and genotypic characterization results of GBS isolates

\begin{tabular}{|c|c|}
\hline & $\begin{array}{l}\text { No. of isolates } \\
\text { (\%) }\end{array}$ \\
\hline \multicolumn{2}{|l|}{ Drug susceptibility testing } \\
\hline Penicillin susceptible & $36 / 36(100 \%)$ \\
\hline Clindamycin susceptible ${ }^{a}$ & $28 / 36(78 \%)$ \\
\hline Clindamycin non-susceptible ${ }^{b}$ & $8 / 36(22 \%)$ \\
\hline Erythromycin susceptible & $28 / 36(78 \%)$ \\
\hline Erythromycin non-susceptible & $8 / 36(22 \%)$ \\
\hline $\mathrm{MLS}_{\mathrm{B}}$ phenotype (inducible clindamycin resistance) & $3 / 36(8 \%)$ \\
\hline $\begin{array}{l}\text { L phenotype (clindamycin resistant, erythromycin } \\
\text { susceptible) }\end{array}$ & $1 / 36(3 \%)$ \\
\hline $\begin{array}{l}\text { M phenotype (clindamycin susceptible, erythromycin } \\
\text { resistant) }\end{array}$ & $1 / 36(3 \%)$ \\
\hline Clindamycin + Erythromycin non-susceptible ${ }^{a}$ & $4 / 36(11 \%)$ \\
\hline Clindamycin + Erythromycin non-susceptible ${ }^{b}$ & $7 / 36(19 \%)$ \\
\hline \multicolumn{2}{|l|}{ Serotyping } \\
\hline Serotype III & $12 / 36(33 \%)$ \\
\hline Serotype V & $11 / 36(31 \%)$ \\
\hline Serotype la & $6 / 36(17 \%)$ \\
\hline Serotype lb & $2 / 36(5 \%)$ \\
\hline Serotype II & $2 / 36(5 \%)$ \\
\hline Serotype IV & $2 / 36(5 \%)$ \\
\hline Serotype VI & $1 / 36(3 \%)$ \\
\hline \multicolumn{2}{|l|}{ Multilocus sequence typing } \\
\hline ST - no exact match & $5 / 36(14 \%)$ \\
\hline ST1 & $4 / 36(11 \%)$ \\
\hline ST19 & $4 / 36(11 \%)$ \\
\hline ST175 & $3 / 36(8 \%)$ \\
\hline ST23 & $2 / 36(6 \%)$ \\
\hline ST249 & $2 / 36(6 \%)$ \\
\hline ST297 & $2 / 36(6 \%)$ \\
\hline Other STs & 14/36 (38\%) \\
\hline \multicolumn{2}{|l|}{ Phenotype association with genotype } \\
\hline $\begin{array}{l}\text { Clindamycin + Erythromycin susceptible/non- } \\
\text { susceptible }^{a}\end{array}$ & $p=0.0129$ \\
\hline ST1 & $0 / 2$ \\
\hline Non-ST1 & $27 / 2$ \\
\hline $\begin{array}{l}\text { Clindamycin + Erythromycin susceptible/non- } \\
\text { susceptible }^{b}\end{array}$ & $p=0.0008$ \\
\hline ST1 & $0 / 4$ \\
\hline Non-ST1 & $27 / 3$ \\
\hline$M L S_{B}$ phenotype negative/positive & $p=0.0060$ \\
\hline ST1 & $0 / 2$ \\
\hline Non-ST1 & $29 / 1$ \\
\hline
\end{tabular}

$M L S_{B}$ Macrolide-lincosamide-streptogramin A, ST Sequence type as determined by multilocus sequence typing

${ }^{a}$ Excluding isolates showing inducible clindamycin resistance by double disk diffusion test

${ }^{\mathrm{b}}$ Including isolates showing inducible clindamycin resistance both clindamycin and erythromycin $(p=0.0129$, when considering constitutive resistance only; $p=0.0008$, when also including inducible clindamycin resistance) and to the $\mathrm{MLS}_{\mathrm{B}}$ phenotype $(p=0.0060$, Table 2$)$. This association was based on small absolute numbers $(n<5)$.

\section{Discussion}

The number of invasive GBS infections in the elderly population is continuously increasing [5], but the reason for this phenomenon is unclear. In Denmark, between 2005 and 2018 the incidence of invasive GBS in adults above the age of 65 years old increased more than twofold (from 3.23 to 8.34 per 100,000). Similar trends have been reported in other countries [8-12]. The prevalence of comorbidities that increase in parallel with age or an increase in GBS colonization have been discussed as potential contributing factors. Although the prevalence of GBS colonization in pregnant women has been investigated in numerous studies, with an average estimate around $20 \%$, the prevalence in the elderly population notably a group with increasing invasive GBS infections - is unknown. The GBS colonization rate is associated with sexual experience and activity [22, 23]. Considering that sexual activity in older people can change over time [24] and may have increased in recent decades, we aimed to determine the vaginal GBS colonization rate in elderly women. Our study showed a prevalence of GBS colonization of $17 \%$ in postmenopausal women (mean age, 68 years), similar to that reported by Moltó-Garcia et al. (17.8\%) in Spain [25]. Edwards et al. reported a colonization rate of $21.7 \%$ in 254 healthy elderly participants (mean age, 73 years) in 2005 [15]. Kaplan et al. found a prevalence of GBS colonization of $12 \%$ among 167 elderly home residents (median age, 84 years) in 1983 [26]. These data indicate that the GBS colonization rate in pregnant women and healthy elderly adults is similar [16].

All GBS isolates preserved susceptibility to penicillin. However, compared with our previous study conducted on GBS isolates from pregnant women tested between 2009 and 2010 in the same geographical area, we observed a higher proportion of isolates that were nonsusceptible to erythromycin ( $22 \%$ vs $14.6 \%$ ), to clindamycin $(14 \%$ vs $8.2 \%)$, and to both clindamycin and erythromycin ( $11 \%$ vs $7.7 \%)$ and that displayed inducible clindamycin resistance ( $8 \%$ vs $5.8 \%$ ) [20]. However, a scientific comparison is not possible, because no longitudinal data were obtained. Moltó-Garcia et al. reported a similar resistance rate to erythromycin (23.4\%) among their GBS samples collected between 2011 and 2012. Although they detected a higher prevalence of constitutive clindamycin resistance (20.6\%), they observed the $M_{L} S_{B}$ phenotype in only $0.9 \%$ of their strains. Increasing trends 
of resistance were also reported elsewhere [7-11, 25, 27]. It is possible that elderly individuals were exposed to antibiotics more frequently than were pregnant women, and hence, GBS isolates display a higher resistance rate. However, we did not make such a comparison in our study.

We found one GBS isolate with L phenotype (clindamycin resistant but erythromycin susceptible). This phenotype is rare and may occur via the inactivation of lincosamide-specific nucleotidyl-transferases encoded by $\ln u$ genes [28]. Alternatively, this unusual mechanism of resistance may also be mediated by the $\mathrm{ABC}$ transporter, encoded by $l s a C$ genes, and be responsible for crossresistance to streptogramin A (LSA phenotype) and pleuromutilins (LSAP phenotype) [29, 30]. Recently, there have been increasing reports of such a phenotype in the United States, Europe, China, Korea and other countries, with a prevalence ranging from $0.26 \%$ in Italy to $15.9 \%$ in Korea [31-34]. This phenotype was detected in one of the most common clones circulating worldwide, ST19. This observation is worrisome because clindamycin is a frequently used alternative in patients with documented allergy to penicillin.

The most prevalent capsular serotypes in our population were III, V and Ia [20]. ST1, ST19 and ST23 were the predominant clones, accounting for $28 \%$ of our isolates. All three STs have been consistently reported to be significantly associated with asymptomatic colonization because of their limited invasive ability [14]. However, when it belongs to capsular serotype V, ST1 has been related to invasive disease, and a possible origin from a bovine ancestor has been hypothesized, similar to the case for hypervirulent clone ST17 [35]. Likewise, ST23 was found in carriage and invasive isolates [36]. Clone ST17 was identified in only one strain.

We confirmed significantly higher rates of resistance to macrolides and clindamycin associated with the genetic background of ST1, belonging to clonal complex 1, as previously described [27]. However, in contrast to Lopes et al., who reported the association of ST1 and capsular serotype Ib, we observed a relation to capsular serotype V [27]. The association of ST1 and capsular serotype $\mathrm{V}$ has also been described elsewhere [37].

Our study has limitations. Because of slow recruitment, the study was terminated prior to reaching the calculated target sample size, ending in a relatively small study population. However, the number of participants was comparable to (or even larger) than those in previous studies, and the GBS prevalence was similar to that of a study that included 600 individuals $[15,25,26]$. We only obtained vaginal and not recto-vaginal swabs, and may have missed an unknown proportion of GBS colonized individuals. However, we are convinced that the potential difference between the two sampling methods did not influence significantly the overall GBS colonization rate in our study population. Eight GBS isolates were lost for phenotypic and genotypic analysis (Fig. 1). Given the lack of association between risk factors, resistance testing and serotype, it is unlikely that the results of these eight lost GBS isolates would have changed the overall findings.

\section{Conclusions}

The GBS vaginal colonization rate in women aged 60 or more was $17 \%$. The observed increase in invasive GBS infections in elderly women may be for reasons other than the colonization rate. We found no associations with patient characteristics, comorbidities, menstrual history, menopause or sexual activity. Twenty-two percent of the isolates were not susceptible to clindamycin, and this pattern was associated with ST1. The most frequently found capsular serotypes were III and V. Our results indicate that the prevalence of colonization, the antibiotic susceptibility and the molecular patterns are similar in pregnant and elderly women.

\section{Abbreviations \\ GBS: Group B Streptococcus; ST: Sequence type; MIC: Minimum inhibitory concentration; $\mathrm{MLS}_{\mathrm{B}}$ : Macrolide-lincosamide-streptogramin B}

\section{Supplementary Information}

The online version contains supplementary material available at https://doi. org/10.1186/s12879-021-06102-x.

\section{Additional file 1.}

\section{Acknowledgements}

We thank Annina Tramèr, RN, and the nursing team of the Department of Gynaecology and Gynaecological Oncology of the University Hospital Basel; Eveline Hediger; and Lilo Schweizer of the University Hospital Bern (Inselspital) for valuable work in the operating procedure issues during the study. We are grateful to the laboratory technicians of the Institute for Infectious Diseases for performing the phenotypic tests of GBS isolates. Barbara Every, ELS, of BioMedical Editor, St Albert, Alberta, Canada, provided English language editing.

\section{Authors' contributions}

PS was the principal investigator and initiated and conducted the study and co-wrote the manuscript. LK, DH, AK and EK recruited the study participants, obtained swabs and completed questionnaires, and had the clinical responsibility for patients. SD and CC processed study participants' samples and performed phenotypic characterization of GBS isolates. SM and BS performed genotypic characterization of GBS isolates. RB designed the study database, analysed the data and co-wrote the manuscript. CB recorded participants' questionnaire data in the study database. All authors revised and approved the manuscript

\section{Funding}

This project was funded by Freie Akademische Gesellschaft Basel and Stiftung für Infektiologie beider Basel. The funding bodies had no role in the design of the study and no role in the collection, analysis, and interpretation of data and in writing the manuscript.

\section{Availability of data and materials}

The data sets used and/or analysed during the current study may be made available upon reasonable written request to the corresponding author. 


\section{Declarations}

\section{Ethics approval and consent to participate}

This study was registered in the ISRCTN registry with trial registration no. ISRCTN15468519. Written informed consent was obtained from all participants. The study was approved by the local ethical committee (Kantonale Ethikkommission-Bern: 2016-01669).

\section{Consent for publication}

Not applicable (included in patient consent and ethics approval).

\section{Competing interests}

The authors declare that they have no competing interests.

\section{Author details}

'Institute for Infectious Diseases, University of Bern, Friedbühlstrasse 51, 3010 Bern, Switzerland. ${ }^{2}$ Department of Gynecology and Obstetrics, Inselspital, Bern University Hospital and University of Bern, Bern, Switzerland. ${ }^{3}$ Outpatient Department \& Colposcopy Unit, University Women's Hospital Basel, Basel, Switzerland. ${ }^{4}$ Institute of Medical Microbiology and Hygiene, University Hospital Ulm, Ulm, Germany. ${ }^{5}$ Division of Infectious Diseases \& Hospital Hygiene, University Hospital Basel and University of Basel, Basel, Switzerland.

\section{Received: 10 October 2020 Accepted: 22 April 2021}

\section{Published online: 03 May 2021}

\section{References}

1. Verani JR, McGee L, Schrag SJ, Division of Bacterial Diseases NCfl, Respiratory Diseases CfDC, Prevention. Prevention of perinatal group B streptococcal disease--revised guidelines from CDC, 2010. MMWR Recomm Rep. 2010; 59(RR-10):1-36.

2. Meyn LA, Krohn MA, Hillier SL. Rectal colonization by group B Streptococcus as a predictor of vaginal colonization. Am J Obstet Gynecol. 2009;201(1):76. e71-7.

3. Dermer P, Lee C, Eggert J, Few B. A history of neonatal group B streptococcus with its related morbidity and mortality rates in the United States. J Pediatr Nurs. 2004;19(5):357-63. https://doi.org/10.1016/j.pedn.2004. 05.012.

4. Farley MM. Group B streptococcal disease in nonpregnant adults. Clin Infect Dis. 2001;33(4):556-61. https://doi.org/10.1086/322696.

5. Skoff TH, Farley MM, Petit S, Craig AS, Schaffner W, Gershman K, et al. Increasing burden of invasive group B streptococcal disease in nonpregnant adults, 1990-2007. Clin Infect Dis. 2009;49(1):85-92. https://doi.org/10.1086/ 599369.

6. Kothari NJ, Morin CA, Glennen A, Jackson D, Harper J, Schrag SJ, et al. Invasive group B streptococcal disease in the elderly, Minnesota, USA, 20032007. Emerg Infect Dis. 2009;15(8):1279-81. https://doi.org/10.3201/eid1508. 081381.

7. Slotved HC, Hoffmann S. The epidemiology of invasive group B Streptococcus in Denmark from 2005 to 2018. Front Public Health. 2020;8: 40. https://doi.org/10.3389/fpubh.2020.00040.

8. Lamagni TL, Keshishian C, Efstratiou A, Guy R, Henderson KL, Broughton K, et al. Emerging trends in the epidemiology of invasive group $B$ streptococcal disease in England and Wales, 1991-2010. Clin Infect Dis. 2013; 57(5):682-8. https://doi.org/10.1093/cid/cit337.

9. Bergseng H, Rygg M, Bevanger L, Bergh K. Invasive group B streptococcus (GBS) disease in Norway 1996-2006. Eur J Clin Microbiol Infect Dis. 2008; 27(12):1193-9. https://doi.org/10.1007/s10096-008-0565-8.

10. Alhhazmi A, Hurteau D, Tyrrell GJ. Epidemiology of invasive group B streptococcal disease in Alberta, Canada, from 2003 to 2013. J Clin Microbiol. 2016;54(7):1774-81. https://doi.org/10.1128/JCM.00355-16

11. Bjornsdottir ES, Martins ER, Erlendsdottir H, Haraldsson G, Melo-Cristino J, Kristinsson KG, et al. Changing epidemiology of group B streptococcal infections among adults in Iceland: 1975-2014. Clin Microbiol Infect. 2016; 22(4):379.e379-16.

12. Ballard MS, Schonheyder HC, Knudsen JD, Lyytikainen O, Dryden M, Kennedy KJ, et al. The changing epidemiology of group B streptococcus bloodstream infection: a multi-national population-based assessment. Infect Dis (Lond). 2016;48(5):386-91. https://doi.org/10.31 09/23744235.2015.1131330.
13. Edwards MS, Baker CJ. Group B streptococcal infections in elderly adults. Clin Infect Dis. 2005;41(6):839-47. https://doi.org/10.1086/432804.

14. Shabayek S, Spellerberg B. Group B streptococcal colonization, molecular characteristics, and epidemiology. Front Microbiol. 2018;9:437. https://doi. org/10.3389/fmicb.2018.00437.

15. Edwards MS, Rench MA, Palazzi DL, Baker CJ. Group B streptococcal colonization and serotype-specific immunity in healthy elderly persons. Clin Infect Dis. 2005;40(3):352-7. https://doi.org/10.1086/426820.

16. Russell NJ, Seale AC, O'Driscoll M, O'Sullivan C, Bianchi-Jassir F, GonzalezGuarin J, et al. Maternal colonization with group B streptococcus and serotype distribution worldwide: systematic review and meta-analyses. Clin Infect Dis. 2017;65(suppl_2):S100-11.

17. Institute CaLS. M100 performance standards for antimicrobial susceptibility testing. 30th ed; 2020.

18. Woods CR. Macrolide-inducible resistance to clindamycin and the D-test. Pediatr Infect Dis J. 2009;28(12):1115-8. https:/doi.org/10.1097/NF.0b013e3181c35cc5.

19. EUCAST. Expert rules. European Commitee on Antimicrobial Susceptibility Testing. https://www.eucast.org/expert_rules_and_intrinsic_resistance/. Accessed 9 Oct 2020.

20. Frohlicher S, Reichen-Fahrni G, Muller M, Surbek D, Droz S, Spellerberg B, et al. Serotype distribution and antimicrobial susceptibility of group B streptococci in pregnant women: results from a Swiss tertiary centre. Swiss Med Wkly. 2014;144:w13935.

21. Poyart C, Tazi A, Reglier-Poupet H, Billoet A, Tavares N, Raymond J, et al. Multiplex PCR assay for rapid and accurate capsular typing of group B streptococci. J Clin Microbiol. 2007;45(6):1985-8. https://doi.org/10.1128/ JCM.00159-07.

22. Manning SD, Neighbors K, Tallman PA, Gillespie B, Marrs CF, Borchardt SM, et al. Prevalence of group B streptococcus colonization and potential for transmission by casual contact in healthy young men and women. Clin Infect Dis. 2004;39(3):380-8. https://doi.org/10.1 086/422321.

23. Foxman B, Gillespie BW, Manning SD, Marrs CF. Risk factors for group B streptococcal colonization: potential for different transmission systems by capsular type. Ann Epidemiol. 2007;17(11):854-62. https://doi.org/10.1016/j.a nnepidem.2007.05.014.

24. Beckman N, Waern M, Ostling S, Sundh V, Skoog I. Determinants of sexual activity in four birth cohorts of Swedish 70-year-olds examined 1971-2001. J Sex Med. 2014;11(2):401-10. https://doi.org/10.1111/jsm.12381.

25. Molto-Garcia B, Liebana-Martos Mdel C, Cuadros-Moronta E, RodriquezGranger J, Sampedro-Martinez A, Rosa-Fraile M, et al. Molecular characterization and antimicrobial susceptibility of hemolytic Streptococcus agalactiae from post-menopausal women. Maturitas. 2016;85:5-10. https:// doi.org/10.1016/j.maturitas.2015.11.007.

26. Kaplan EL, Johnson DR, Kuritsky JN. Rectal colonization by group B betahemolytic streptococci in a geriatric population. J Infect Dis. 1983;148(6): 1120. https://doi.org/10.1093/infdis/148.6.1120.

27. Lopes E, Fernandes T, Machado MP, Carrico JA, Melo-Cristino J, Ramirez M, et al. Increasing macrolide resistance among Streptococcus agalactiae causing invasive disease in non-pregnant adults was driven by a single capsular-transformed lineage, Portugal, 2009 to 2015. Euro Surveill. 2018; 23(21):1700473.

28. Achard A, Villers C, Pichereau V, Leclerca R. New Inu(C) gene conferring resistance to lincomycin by nucleotidylation in Streptococcus agalactiae UCN36. Antimicrob Agents Chemother. 2005;49(7):2716-9. https://doi.org/1 0.1128/AAC.49.7.2716-2719.2005.

29. Malbruny B, Werno AM, Anderson TP, Murdoch DR, Leclerca R. A new phenotype of resistance to lincosamide and streptogramin A-type antibiotics in Streptococcus agalactiae in New Zealand. J Antimicrob Chemother. 2004;54(6):1040-4. https://doi.org/10.1093/jac/dkh493.

30. Malbruny B, Werno AM, Murdoch DR, Leclercq R, Cattoir V. Cross-resistance to lincosamides, streptogramins A, and pleuromutilins due to the Isa(C) gene in Streptococcus agalactiae UCN70. Antimicrob Agents Chemother. 2011;55(4):1470-4. https://doi.org/10.1128/AAC.01068-10.

31. Hawkins PA, Law CS, Metcalf BJ, Chochua S, Jackson DM, Westblade LF, et al. Cross-resistance to lincosamides, streptogramins A and pleuromutilins in Streptococcus agalactiae isolates from the USA.J Antimicrob Chemother. 2017;72(7):1886-92. https://doi.org/10.1093/jac/dkx077.

32. Arana DM, Rojo-Bezares B, Torres C, Alos II. First clinical isolate in Europe of clindamycin-resistant group B Streptococcus mediated by the Inu(B) gene. Rev Esp Quimioter. 2014;27(2):106-9. 
33. Zhou K, Zhu D, Tao Y, Xie L, Han L, Zhang Y, et al. New genetic context of Inu(B) composed of two multi-resistance gene clusters in clinical

Streptococcus agalactiae ST-19 strains. Antimicrob Resist Infect Control. 2019; 8(1):117. https://doi.org/10.1186/s13756-019-0563-x.

34. Takahashi T, Maeda T, Lee S, Lee DH, Kim S. Clonal distribution of clindamycin-resistant erythromycin-susceptible (CRES) Streptococcus agalactiae in Korea based on whole genome sequences. Ann Lab Med. 2020;40(5):370-81. https://doi.org/10.3343/alm.2020.40.5.370.

35. Salloum M, van der Mee-Marquet N, Valentin-Domelier AS, Quentin R. Diversity of prophage DNA regions of Streptococcus agalactiae clonal lineages from adults and neonates with invasive infectious disease. PLoS One. 2011;6(5):e20256. https://doi.org/10.1371/journal.pone.0020256.

36. Jones N, Bohnsack JF, Takahashi S, Oliver KA, Chan MS, Kunst F, et al. Multilocus sequence typing system for group B streptococcus. J Clin Microbiol. 2003:41(6):2530-6. https://doi.org/10.1128/JCM.41.6.2530-2536.2 003

37. Luan SL, Granlund M, Sellin M, Lagergård T, Spratt BG, Norgren M. Multilocus sequence typing of Swedish invasive group B streptococcus isolates indicates a neonatally associated genetic lineage and capsule switching. J Clin Microbiol. 2005;43(8):3727-33. https://doi.org/10.1128/ JCM.43.8.3727-3733.2005

\section{Publisher's Note}

Springer Nature remains neutral with regard to jurisdictional claims in published maps and institutional affiliations.

Ready to submit your research? Choose BMC and benefit from:

- fast, convenient online submission

- thorough peer review by experienced researchers in your field

- rapid publication on acceptance

- support for research data, including large and complex data types

- gold Open Access which fosters wider collaboration and increased citations

- maximum visibility for your research: over $100 \mathrm{M}$ website views per year

At BMC, research is always in progress.

Learn more biomedcentral.com/submissions 